\title{
Apple and Peach Leaf and Stem Surface Morphology and Soybean Oil Retention as Influenced by Simulated Rainfall and Soybean Oil Emulsions
}

\author{
B.R. Bondada, C.E. Sams, D.E. Deyton, and J.C. Cummins \\ Department of Plant and Soil Sciences, P.O. Box 1071, The University of Tennessee, Knoxville, TN 37901
}

AdDITIONAL INDEX wORDs. epicuticular wax, lenticel, Malus sylvestris var. domestica, electron microscopy, Prunus persica, stomates

\begin{abstract}
Environmental factors such as rainfall may reduce the efficacy of foliar-applied soybean [Glycine max (L.) Merrill] oil in reducing pest mortality. Greenhouse studies were conducted to investigate the influence of rain on the retention of soybean oil and the influence of soybean oil and rainfall on surface morphology of apple [Malus sylvestris (L.) Mill var. domestica (Borkh.) Mansf.] and peach [Prunus persica $\left(\right.$ L. $_{\text {. }}$ Batsch (Peach Group)] leaves and stems. 'Contender' peach and 'Golden Delicious'/Malling 27 apple trees were grown in $19 \mathrm{~L}$ pots in a greenhouse $\left(23 \pm 9^{\circ} \mathrm{C}\right)$ and sprayed with soybean oil (1\%) emulsified with the adjuvants Latron B-1956 or K1. Twenty-four hours after treatment, the trees were subjected to simulated rainfall of $0.0,0.25,1.25$, or $2.54 \mathrm{~cm}$. A negative linear relationship existed between rainfall and oil retention. Peach leaves receiving $0.25,1.25$, and $2.54 \mathrm{~cm}$ rainfall retained $81 \%, 38 \%$, and $18 \%$ of the applied oil, respectively. Oil retention by apple leaves was also negatively related to rainfall. For both species, a negative linear relationship existed between oil retention on stems and rainfall. There was no effect of emulsifier on retention of $1 \%$ soybean oil after rain on apple leaves or on the retention of $8 \%$ to $11 \%$ soybean oil on the stems of apple and peach. Scanning electron microscopy revealed that epicuticular wax occurred as striations on apple and peach leaves. The wax morphology on peach and apple stems appeared as thin plates and platelets, respectively. The wax morphology of leaves and stems of both trees was not affected either by the soybean oil emulsions or rain. Both emulsions induced stomatal closure in leaves and peach stems, however, stomates opened after rainfall of 1.25 or $2.54 \mathrm{~cm}$. The lenticels appeared to be unaffected by either emulsion. Results illustrate that rainfall of $2.54 \mathrm{~cm}$ washed off a major portion of the applied oil. Thus, respraying may be needed under natural climatic conditions with rainfall $\geq 2.54 \mathrm{~cm}$ to restore the efficacy of applied soybean oil.
\end{abstract}

One of the major environmental factors determining the efficacy of foliar-applied insecticides in orchard crops is rain. Rain removes deposits of insecticide from the foliage surface and reduces pest mortality (McDowell et al., 1984). Studies have shown that simulated rain of 2 to $5 \mathrm{~mm}$ washes off $50 \%$ or more of the original deposit of insecticides (Pick et al., 1984). Such removal leads to repeated spray applications which increase chemical, fuel, labor, and machinery expenses (Mashaya, 1993).

Retention of spray droplets is a function of the properties of the spray solution such as viscosity and target surface morphology (Baker, 1974; Wirth et al., 1991). Compounds with high viscosity are added to spray mixtures to increase spray retention by the target surface (Reichard and Zhu, 1996). Soybean (Glycine max) oil is an environmentally safe compound that controls various insects and mites of apple (Malus sylvestris var. domestica) and peach [Prunus persica (Peach Group)] trees (Pless et al., 1995), delays peach bloom, and thins fruit (Myers et al., 1996). Before being used as a spray, the soybean oil must be formulated with an emulsifier. There are numerous compounds available as emulsifying agents which vary greatly in their viscosities. Emulsified soybean oil when deposited on the target surfaces may be washed off by rain. Information on the impact of rain on soybean oil deposits will allow growers and researchers to determine if respraying is needed. Therefore, the objectives of this study were to 1) quantify the

Received for publication 30 Nov. 1999. Accepted for publication 17 Apr. 2000. This project was supported by a grant from the United Soybean Board and by the Tennessee Agricultural Experiment Station. The adjuvants K1 and Latron B-1956 were provided by Central Soya Co. and Rohm Haas Co., respectively. We gratefully acknowledge Ron Yoder, Department of Agricultural and Biosystem Engineering, for supplying the rain simulator and providing technical assistance. Thanks are also due to Richard Williams and John Dunlop of the Department of Biology for technical guidance in sample preparation and scanning electron microscopy. The cost of publishing this paper was defrayed in part by the payment of page charges. Under postal regulations, this paper therefore must be hereby marked advertisement solely to indicate this fact. amount of soybean oil retained after rain, 2) investigate the influence of an emulsifier on soybean oil retention after rain, and 3) determine the impact of soybean oil emulsions and rain on leaf and stem surface morphology.

\section{Materials and Methods}

RAINFALL EFFECT ON SOYBEAN OIL RESIDUES ON PEACH FOLIAGE (EXPT. 1). Twenty-five 2-year-old 'Contender' peach trees were planted 27 Mar. 1997 in $19 \mathrm{~L}$ pots with a medium of 4 pine bark : 1 sand $(\mathrm{v} / \mathrm{v})$ amended with $170 \mathrm{~g} \cdot \mathrm{m}^{-3}$ of epsom salts, $170 \mathrm{~g} \cdot \mathrm{m}^{-3}$ of dolomitic lime, and $330 \mathrm{~g} \cdot \mathrm{m}^{-3}$ of $15 \mathrm{~N}-4 \mathrm{P}-10 \mathrm{~K}$ Osmocote (The Scotts Co., Columbus, Ohio). Each pot was top dressed after planting with $15 \mathrm{~g}$ of $14 \mathrm{~N}-4.2 \mathrm{P}-11.6 \mathrm{~K}$ Osmocote. The plants were pruned to a single stem (central leader) and grown in a greenhouse. Soybean oil (1\%, v/v) emulsified with Latron B-1956 spreader sticker, a nonionic surfactant (10\% of oil) (Rohm and Haas Co., Philadelphia, Pa.) was sprayed to runoff on trees on 7 Oct. using a back pack mist blower. Latron has a viscosity of 152 centipoise at $25{ }^{\circ} \mathrm{C}$ (Bondada et al., 1998). Trees were sprayed outside the greenhouse and then immediately moved back into the house. The rain treatments were applied $24 \mathrm{~h}$ after spraying. The treatments consisted of 1) control (no soybean oil spray), 2) 1\% soybean oil with Latron $+0.0 \mathrm{~cm}$ rain, 3) $1 \%$ soybean oil with Latron $+0.25 \mathrm{~cm}$ rain, 4) $1 \%$ soybean oil with Latron $+1.25 \mathrm{~cm}$ rain, and 5) $1 \%$ soybean oil with Latron $+2.54 \mathrm{~cm}$ rain. The experiment was conducted in a randomized complete block design with five replications. The average temperature and relative humidity during the experiment were $23 \pm 9^{\circ} \mathrm{C}$ and $73 \% \pm 13 \%$, respectively. The plants were grown in ambient light and had a photoperiod of $12 \mathrm{~h} 45 \mathrm{~min}$ light/11 h 15 min dark on the spray date.

Rain SimUlation. Rain was simulated using a rain simulator with an irrigation nozzle (4 $\mathrm{mm}$ in diameter) (Nelson Irrigation Corp., Walla Walla, Wash.) mounted $1.8 \mathrm{~m}$ above the canopy in the 
greenhouse. The rain simulator produced a droplet spectrum similar to that of natural rain $(0.5$ to $5.0 \mathrm{~mm})$. The rain simulator was connected by a garden hose to a tap which supplied water through a regulating valve (Senninger Irrigation, Inc., Orlando, Fla.) that was adjusted to give a constant working pressure of $69 \mathrm{kPa}$. The quantity of water delivered was measured by eight rain gauges arranged on the ground in circles of $0.9 \mathrm{~m}$ and $1.5 \mathrm{~m}$ radius around the rain simulator. Water was collected in the gauges at different time intervals to determine the amount of time required to deliver the desired amount of rain. The rain simulator delivered $0.25,1.25$, and $2.54 \mathrm{~cm}$ rain in 10,45 , and $90 \mathrm{~min}$, respectively.

RAINFALL EFFECT ON SOYBEAN OIL RESIDUES ON APPLE FOLIAGE (EXPT. 2). Two-year-old 'Golden Delicious'/Malling 27 (M.27) apple trees were potted on 20 Mar. 1997 in 19-L pots in the same medium and with the same fertilization as in Expt. 1. The experiment was conducted in a manner analogous to Expt. 1. The trees were sprayed on 23 Oct. with $1 \%$ soybean oil emulsified with Latron B-1956 or K1, a nonionic emulsifier, (10\% of oil) (an experimental emulsifier from Central Soya, Fort Wayne, Ind.). K1 has a viscosity of 5480 centipoise at $25^{\circ} \mathrm{C}$ (Bondada et al., 1998). The trees were subjected to the same rainfall regimes as in Expt. 1. The experiment was conducted in a randomized complete block design with five replications. The average temperature and relative humidity during the experiment were $21 \pm 8^{\circ} \mathrm{C}$ and $70 \% \pm 11 \%$, respectively. The plants were grown in ambient light and had a photoperiod of $11 \mathrm{~h} 53$ min light/12 h 7 min dark on the spray date.

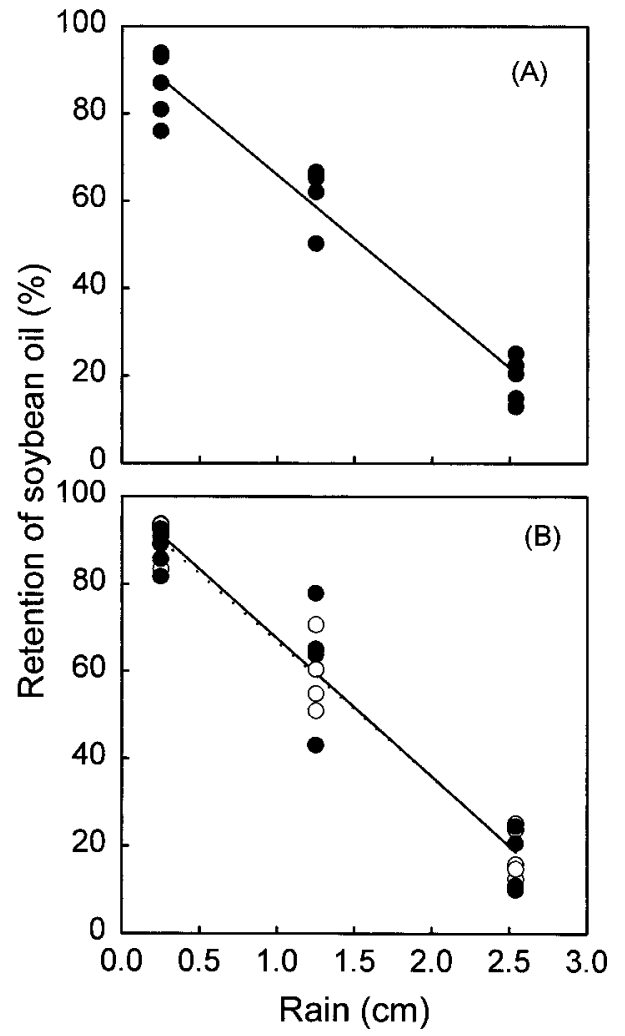

Fig. 1. (A) Effect of rain on retention of soybean oil emulsified with Latron B-1956 ( $\mathrm{y}=95.4-29.4 \mathrm{x}, r^{2}$ $=0.95)$ by peach leaves, and (B) effect of rain on retention of soybean oil emulsified with Latron B-1956 $\left(\bigcirc, \mathrm{y}=99.3-31.7 \mathrm{x}, r^{2}=0.97\right)$ and soybean oilemulsified with $\mathrm{K} 1\left(\mathbf{0}, \mathrm{y}=97.8-31.0 \mathrm{x}, r^{2}=0.93\right)$ by apple leaves. The slopes of regression equations for retention of soybean oil emulsified with Latron and K1 were not significantly different at $P \leq 0.05$ by Students paired $t$ test. Each point represents the mean of six leaves.

RAINFALL EFFECT ON SOYBEAN OIL RESIDUES ON DORMANT STEMS (EXPT. 3). Forty-five dormant 2-year-old 'Contender' peach and forty-five dormant 2-year-old 'Golden Delicious'/M.27 apple trees were potted on 20 Mar. 1997 in 19-L pots in the same medium and with the same fertilization as in Expt. 1. The trees were moved outdoors to a cold frame in early Nov. After defoliation, the trees were moved backed inside the greenhouse. The peach and apple trees were sprayed on 5 Feb. 1998 with $8 \%(\mathrm{v} / \mathrm{v})$ and 11\% (v/v) soybean oil emulsified with Latron B-1956 (10\% of soybean oil) and K1 (10\% of soybean oil), respectively. The trees were then moved back into the greenhouse. We chose $8 \%$ and $11 \%$ soybean oil concentrations for peach and apple trees, respectively, because these concentrations have been shown to be desirable for bloom delay in peach (Myers et al., 1996) and apple (unpublished data). The treatments consisted of (1) control (no oil spray), (2) soybean oil with Latron as the emulsifier with $0.0 \mathrm{~cm}$ rain, (3) soybean oil with Latron $+0.25 \mathrm{~cm}$ rain, (4) soybean oil with Latron $+1.25 \mathrm{~cm}$ rain, (5) soybean oil with Latron $+2.54 \mathrm{~cm}$ rain, (6) soybean oil with $\mathrm{K} 1$ as the emulsifier $+0.0 \mathrm{~cm}$ rain, (7) soybean oil with $\mathrm{K} 1+0.25$ $\mathrm{cm}$ rain, (8) soybean oil with $\mathrm{K} 1+1.25 \mathrm{~cm}$ rain, and (9) soybean oil with $\mathrm{K} 1+2.54 \mathrm{~cm}$ rain. The experiment was conducted in a randomized complete block design with five replications and two stem samples per replication. The average temperature and relative humidity during the experiment were $20 \pm 4^{\circ} \mathrm{C}$ and $50 \% \pm 8 \%$, respectively. The plants were grown in ambient light and had a photoperiod of $11 \mathrm{~h} 27 \mathrm{~min}$ light/12 h 33 min dark on the spray date.

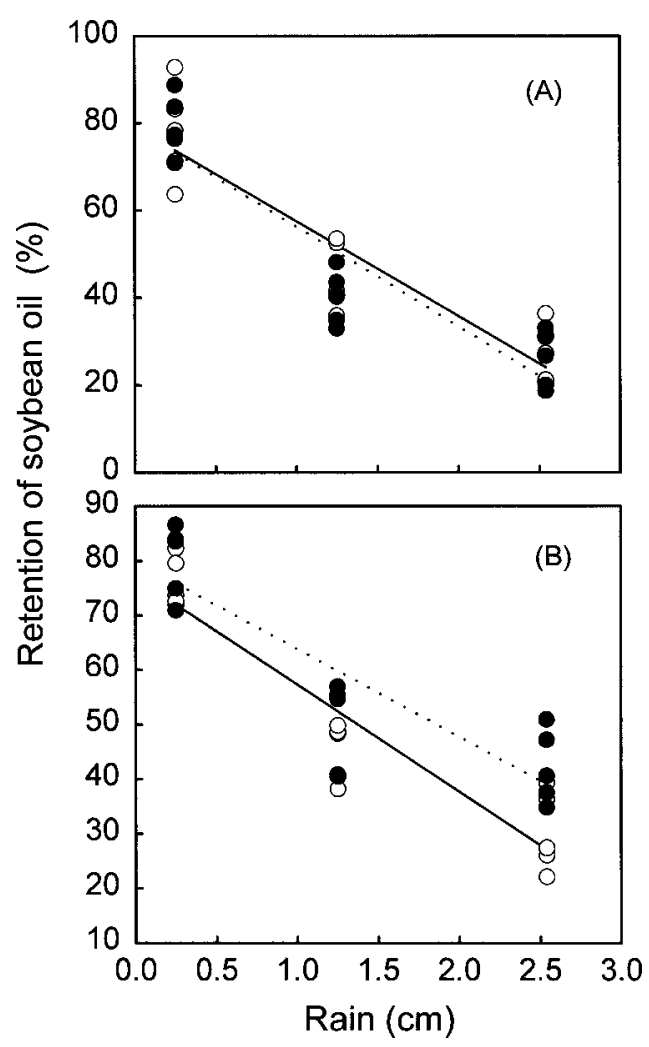

Fig. 2. (A) Effect of rain on retention of soybean oil emulsified withLatron B-1956(O,y=79.3-21.7x, $\left.r^{2}=0.82\right)$ and $\mathrm{K} 1(\mathbf{O}$, $\left.\mathrm{y}=79.1-22.8 \mathrm{x}, r^{2}=0.83\right)$ by peach stems, and $(\mathbf{B})$ effect of rain on retention of soybean oil emulsified with Latron B$1956\left(\bigcirc, \mathrm{y}=76.9-19.6 \mathrm{x}, r^{2}=0.86\right)$ and $\mathrm{K} 1(\boldsymbol{O}, \mathrm{y}=79.9$ $\left.16.1 \mathrm{x}, r^{2}=0.79\right)$ by apple stems. The slopes of regression equations forretention of soybean oilof soybeanoilemulsified withLatron and $\mathrm{K} 1$ were not significantly different at $P \leq 0.05$ for peach or apple stems as indicated by Students paired $t$ test. Each point represents the mean of two stems.
DETERMINATION OF OIL CONTENT AND RETENTION. To measure oil content and oil retention in Expts. 1 and 2, nine leaves (three leaves from each of the apical, middle, and basal portions of a shoot) were harvested from each tree $24 \mathrm{~h}$ after the oil sprays were applied. After subjecting the trees to the three rain regimes, another nine leaves per tree were collected to determine oil retention. Leaf areas were measured using a LI-3000 leaf area meter (LICOR, Lincoln, Nebr.).

The oil and wax content were determined gravimetrically by immersing each leaf three times (each immersion lasted for $10 \mathrm{~s}$ ) in previously weighed test tubes $(25 \times 150$ $\mathrm{mm}$ ) containing $30 \mathrm{~mL}$ chloroform (pesticide grade, Fisher, Pittsburgh, Pa.). The wax and oil content were determined by evaporating the chloroform with nitrogen and reweighing the test tubes. The wax and oil content were calculated by subtracting the initial weight of the test tube from its final weight and expressed as $\mathrm{g} \cdot \mathrm{cm}^{-2}$ of leaf. To determine the oil content, the average wax concentration from control plants was subtracted from the final weight of each test tube containing wax and oil together before and after the rain, and the oil content was expressed as $\mathrm{g} \cdot \mathrm{cm}^{-2}$ of leaf. To calculate oil re- 
tention, the oil content after rain was subtracted from oil content before rain and expressed as percent retention.

For determining oil retention in Expt. 3, stems $5 \mathrm{~cm}$ in length were sampled before and after the rain. The diameter of the stems was measured using a vernier caliper and the surface areas of the stems were calculated using the surface area formula of a cylinder. Oil retention by stems was determined in a similar manner as described for the leaves.

Scanning Electron microscopy. Two leaf discs (9 $\mathrm{mm}$ in diameter $)$ and bark $(8 \times 4 \mathrm{~mm})$ from stems were taken from each treatment using a cork borer and a razor blade, respectively. The leaf discs from adaxial and abaxial surfaces and the bark, with exterior surface exposed, were affixed to aluminum stubs using Avery (Electron Microscopy Sciences, Fort Washington, Pa.) self adhesive paper tacks. The discs and bark were then air dried in a desiccator. The stubs were coated with $\approx 100 \AA$ of gold-palladium (60:40) on a Hummer sputter coater (Anatech LTD., Alexander, Va.) and observed on an autoscan Scanning Electron Microscope (ETEC, Hayward, Calif.) operating at $10 \mathrm{kV}$ at $100 \mu \mathrm{A}$ current.

\section{Results and Discussion}

Results from Expts. 1 and 2 showed a significant negative linear relationship $(P \leq 0.05)$ between rainfall and oil retention by peach and apple leaves (Fig. 1). Peach leaves sprayed with $1 \%$ soybean oil plus Latron and then receiving $0.25,1.25$ or $2.54 \mathrm{~cm}$ rain retained $82 \%, 38 \%$, or $18 \%$ of the applied oil, respectively (Fig. 1A). Wash off studies with insecticides have shown that simulated rain of 2 to $5 \mathrm{~mm}$ removed $50 \%$ or more of the original deposits of insecticides (Pick et al., 1984). Apple leaves receiving 1\% soybean oil emulsified with Latron or K1 also exhibited negative linear relationships with rain (Fig. 1B). The slopes of regression equations for soybean oil emulsified with Latron or K1 were not significantly different $(P$ $\leq 0.05)$. Thus, type of emulsifier had no effect on oil retention after rain (Fig. 1B).

The third experiment showed that a major portion of the oil applied to stems was lost after $2.54 \mathrm{~cm}$ of rain (Fig. 2). Peach and apple stems sprayed with soybean oil emulsified with Latron had $77 \%, 31 \%$, and $26 \%$; and $78 \%, 46 \%$, and $31 \%$ oil retention after rain of $0.25,1.25$, and $2.54 \mathrm{~cm}$, respectively. Peach and apple stems sprayed with soybean oil emulsified with $\mathrm{K} 1$ had $80 \%, 46 \%$, and $26 \%$; and $80 \%, 47 \%$, and $38 \%$ retention, respectively, after the same rain regime (Fig. 2). The oil washed off from the two emulsions was not significantly different $(P \leq 0.05)$ on stems (Fig. 2). Thus, analogous to apple leaves, oil retention by apple and peach stems was similar regardless of emulsifier.

Scanning electron microscopy revealed that the epicuticular wax occurred as striations on adaxial and abaxial surfaces of peach (Fig. 3A and B) and apple leaves (Fig. 4A and B) as reported previously by Leece (1976). There was a heavy accumulation of wax in layers around the stomates of peach leaves (Fig. 3B). Such an enclosure of stomates by wax layers was not observed in apple leaves (Fig. 4B). Striated epicuticular wax morphology has also been observed on leaves and fruits of other crops such as cotton (Gossypium hirsutum L.) ( Bondada et al., 1996; Bondada et al., 1994).

The epicuticular waxes on both surfaces of peach leaves did not appear to be affected by $1 \%$ soybean oil plus Latron (Fig. 3C and D) and rain (Fig. 3E and F). Also, the soybean oil emulsion with K1 (Fig. 4C and D) or Latron and rain (Fig. 4E and F) had no effect on wax morphology of apple leaves. Since there was no effect on wax morphology by either soybean emulsion, only the leaf surfaces sprayed with soybean oil plus K1 are illustrated in Fig. 4. Applica- tion of pure soybean oil at $9 \mathrm{~L} \cdot \mathrm{ha}^{-1}$ dissolved wax plates on leaf surfaces of Johnsongrass [Sorghumhalapense (L.)Pers.] (McWhorter and Barrentine, 1988). However, our use of a low rate of soybean oil may be the reason why we did not observe any dissolution or alteration of waxes in this study. Another explanation could be the disparities in chemical composition of waxes. In Johnsongrass, the wax occurred as platelets (McWhorter and Barrentine, 1988) and thus may have had a different chemical composition from the wax on apple and peach leaves.

It has been reported that spray oils (petroleum oil, vegetable oil, mineral oil, and citrus oil) penetrate through stomata causing damage to stomatal apparatus and eventually phytotoxicity (Davidson et al., 1991; Gudin et al., 1976; Van Overbeek and Blondeau, 1954). In our study, stomates were not distorted or deformed, suggesting that soybean oil did not enter the stomata and thus was not toxic (Figs. 3D and 4D). It has been suggested that stomatal penetration would be obtained with oil (paraffinic oil) when stomates were sunken in relation to surrounding cells (Gudin et al., 1976; Van Overbeek and Blondeau, 1954). The stomates on apple and peach
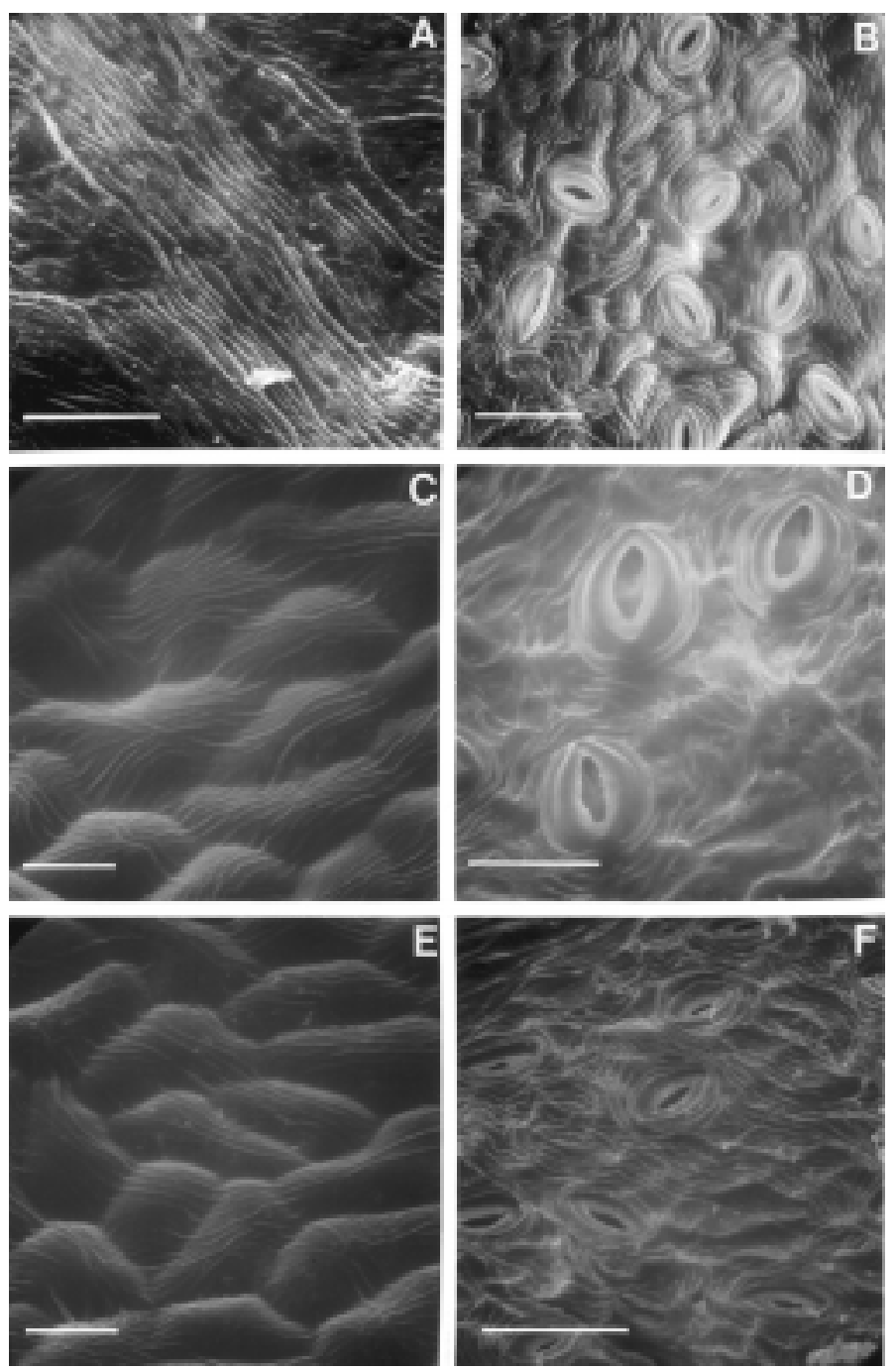

Fig. 3. Scanning electron micrographs of peach leaves. (A) Control adaxial (560x) and (B) control abaxial (440×) leaf surfaces. (C) Adaxial (960×) and (D) abaxial $(1120 \times)$ leaf surfaces sprayed with soybean oil + Latron B-1956. (E) Adaxial $(960 \times)$ and $($ F) abaxial $(600 \times)$ leaf surfaces sprayed with soybean oil + Latron B1956 and then subjected to $2.54 \mathrm{~cm}$ rain. Scale bars: $\mathrm{A}=50 \mu \mathrm{m}, \mathrm{B}=20 \mu \mathrm{m}, \mathrm{C}=$ $20 \mu \mathrm{m}, \mathrm{D}=20 \mu \mathrm{m}, \mathrm{E}=20 \mu \mathrm{m}$, and $\mathrm{F}=50 \mu \mathrm{m}$. 

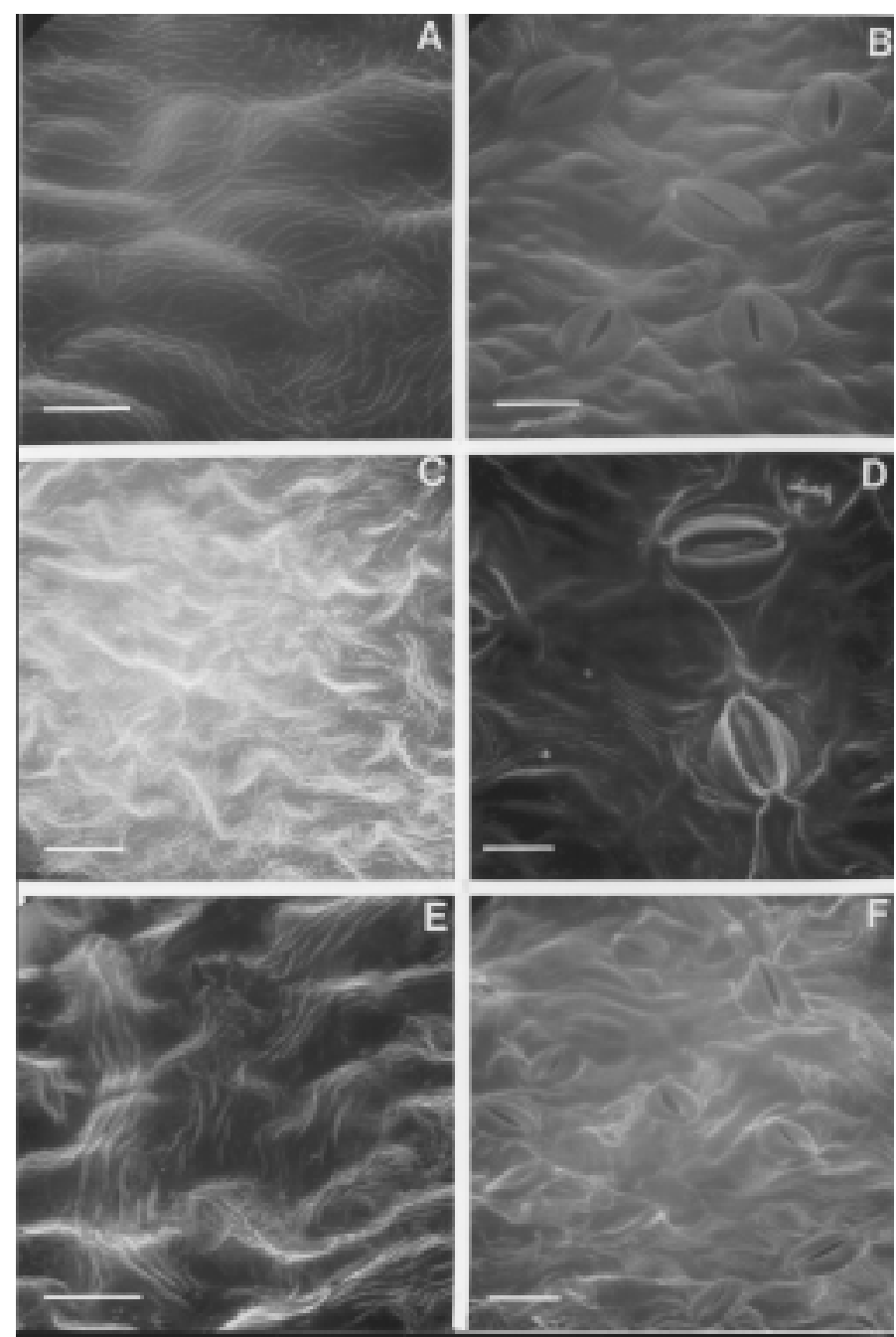

Fig. 4. Scanning electron micrographs of apple leaves. (A) Control adaxial (920X) and (B) control abaxial (920×) leaf surfaces. (C) Adaxial (600×) and (D) abaxial (1500×) leaf surfaces sprayed with soybean oil + K1. (E) adaxial $(1040 \times)$ and $(F)$ abaxial $(520 \times)$ leaf surfaces sprayed with soybean oil $+\mathrm{K} 1$ and then subjected to $2.54 \mathrm{~cm}$ rain. Scale bars: $\mathrm{A}=20 \mu \mathrm{m}, \mathrm{B}=20 \mu \mathrm{m}, \mathrm{C}=20 \mu \mathrm{m}, \mathrm{D}=10 \mu \mathrm{m}, \mathrm{E}=20 \mu \mathrm{m}$, and $\mathrm{F}=30 \mu \mathrm{m}$.

leaves are flush with the surface (Figs. 3 and 4). This may explain why soybean oil did not penetrate through apple and peach stomates. Furthermore, especially in the case of peach, the likelihood of soybean oil gaining entry through stomates is remote as the stomates were enclosed by a heavy buildup of wax (Fig. 3B). Although there was no stomatal damage, both soybean emulsions induced stomatal closure (Figs. 3D and 4D). Since variations of stomatal apertures control the flux of $\mathrm{CO}_{2}$ and water vapor, stomatal closure induced by soybean oil spray may affect gas exchange. Studies in our laboratory have shown reductions in photosynthesis for up to a week after soybean oil spray application (unpublished data). In addition to soybean oil, other spray oils such as petroleum oil have also been reported to decrease net gas exchange in apple (Ferree et al., 1976), citrus (Citrus ×paradisi Macfad.) (Syvertsen and Salyani, 1991), and pecan [Carya illinoinensis (Wangenh.) K. Koch] leaves (Wood and Payne, 1986).

There are no previous reports on wax morphology of peach or apple stems. Epicuticular wax occurred as thin plates on the peach stem exterior surfaces (Fig. 5A). This wax morphology of stems differed from the striated appearance on the leaf surfaces, (Fig. 3) but was analogous to that of barley (Hordeum vulgare L.) leaf surfaces (Wirth et al., 1991). The wax morphology of stems also remained unaltered by soybean oil emulsions (Fig. 5B) and rain (Fig. 5D), thus, only the surfaces which were sprayed with soybean oil plus K1 are illustrated in Fig. 5. Stomates were observed on both stem and leaf surfaces. However, there were fewer stomates on the stem surfaces than on the leaf surfaces. Furthermore, the stomates on peach stem surfaces were sunken (Fig. 5A, C, and D). Similar to leaves, stem stomates were induced to close, (Fig. 5C) but not damaged or deformed by oil application and opened after the rain (Fig. 5D). This may explain the increased internal $\mathrm{CO}_{2}$ concentration of peach stems on dormant peach trees following soybean oil application (Myers et al., 1996). The presence of stomates on peach stem surfaces suggests that peach stems are also capable of taking part in gas exchange processes. However, compared to leaves, stems would be less efficient in gas exchange due to the low number of small sunken stomates. Also, transpiration from stems would be less than from leaves due to the greater length of the diffusion gradient of water-vapor through sunken stomates (Meyer and Anderson, 1968).

Van Overbeek and Blondeau (1954) and Gudin et al. (1976) have reported that sunken stomates are more prone to penetration by oil (paraffinic oil). However, we did not observe this phenomenon in stem stomates. The diameter of stomatal aperture and viscosity of spray solutions determine stomatal penetration by liquids (Dybing and Currier, 1961; Schonherr and Bukovac, 1972; Turrell, 1947). Since stomates on stem surfaces were smaller than the corresponding leaf stomates, the stomatal aperture of stem stomates may be too small to be easily penetrated by soybean oil. Another explanation for this difference is that in previous studies, Van Overbeek and Blondeau (1954) and Gudin et al. (1976) used paraffinic oil which is different from soybean oil in physicochemical properties.

Peach stems had lens shaped, convex lenticels arranged in longitudinal rows between the stomates (Fig. 6A). Lenticels are loosely arranged parenchyma cells which function in gas exchange
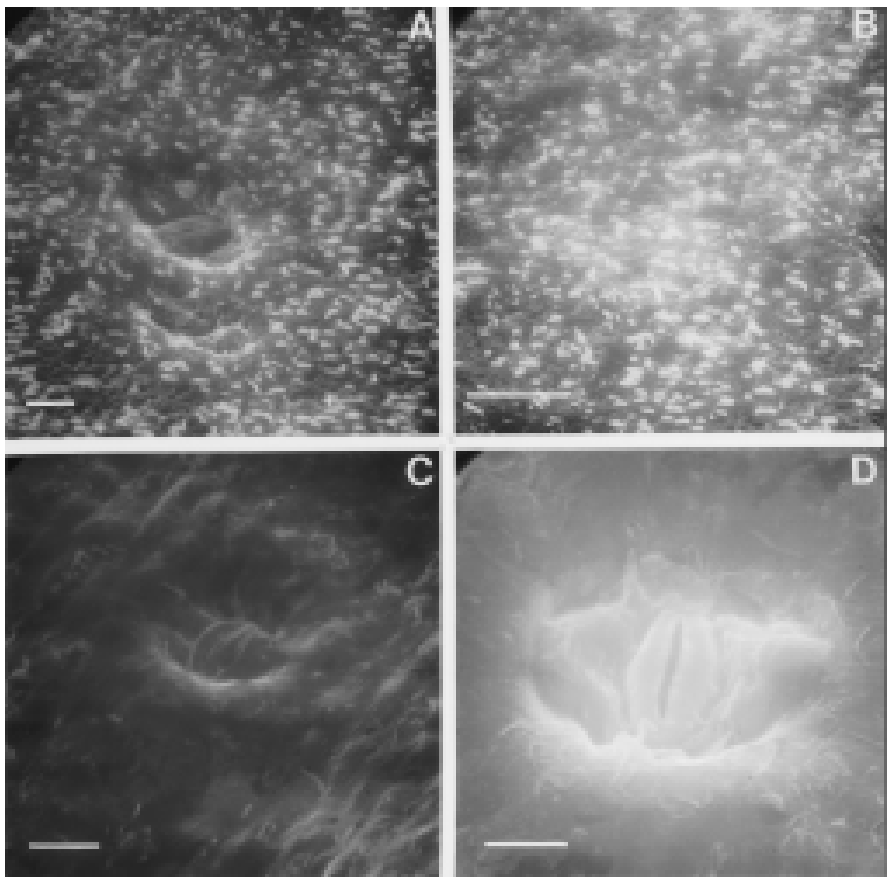

Fig. 5. Scanning electron micrographs of peach stems of (A) control (560×), (B) sprayed with soybean oil + K1 (440×), (C) sprayed with soybean oil + K1 (300×), and (D) sprayed with soybean oil $+\mathrm{K} 1$ and exposed to $2.54 \mathrm{~cm}$ rain $(880 \times)$. Scale bars: $\mathrm{A}=20 \mu \mathrm{m}, \mathrm{B}=50 \mu \mathrm{m}, \mathrm{C}=50 \mu \mathrm{m}$, and $\mathrm{D}=20 \mu \mathrm{m}$. 

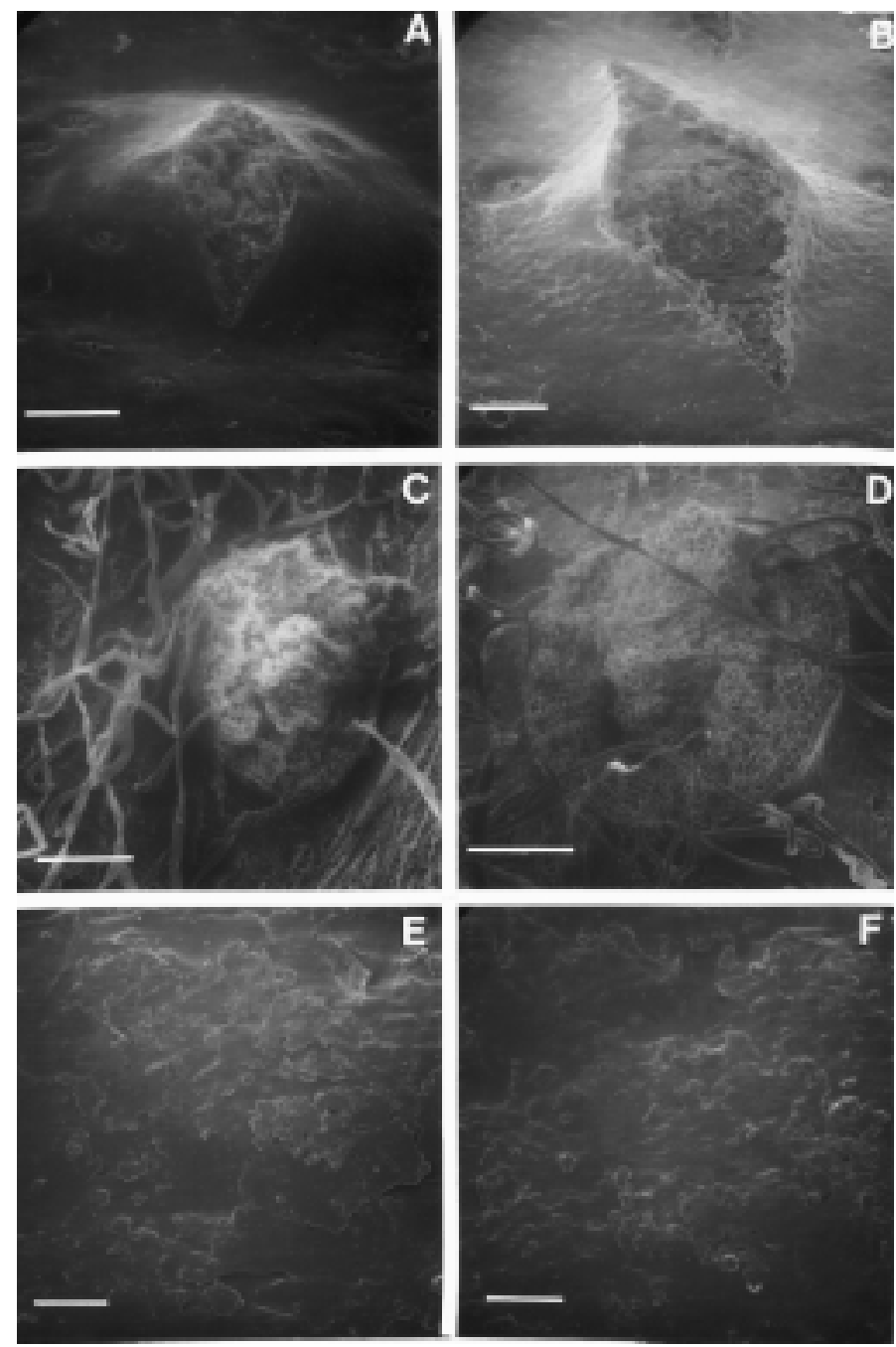

Fig. 6. (A) Lenticel with stomates $(960 \times)$ on control peach stem and (B) lenticel on peach stem sprayed with soybean oil + K1 $(1600 \times)$. (C) Lenticel $(1040 \times)$ on control apple stem and (D) lenticel on apple stem sprayed with soybean oil + K1 $(1100 \times)$. (E) Epicuticular wax on control apple stem $(320 \times)$ and $(\mathbf{F})$ epicuticular wax on apple stem sprayed with soybean oil $+\mathrm{K} 1(320 \times)$. Scale bars: $A=20 \mu \mathrm{m}$, $\mathrm{B}=10 \mu \mathrm{m}, \mathrm{C}=20 \mu \mathrm{m}, \mathrm{D}=20 \mu \mathrm{m}, \mathrm{E}=50 \mu \mathrm{m}$, and $\mathrm{F}=50 \mu \mathrm{m}$.

between the air and the interior of the stem (Fahn, 1990). In the present study, lenticels did not appear to be damaged by soybean oil application (Fig. 6B). Nonetheless, since lenticels are loosely arranged parenchyma cells, they were expected to be filled with soybean oil which perhaps is better seen in a cross section of the lenticel under cryoscanning electron microscopy. Myers et al. (1996) reported that a thin film of soybean oil covering peach stem surfaces increased internal $\mathrm{CO}_{2}$ concentration. Thus, the increased internal $\mathrm{CO}_{2}$ concentration following soybean oil application in peach stems (Myers et al., 1996) was due to stomatal closure (Fig. 5C) and the blocking of lenticels with soybean oil.

In contrast to peach stems, the lenticels on apple stems were round (Fig. 6C) but arranged in longitudinal rows. Analogous to peach stems, the lenticels on apple stems exhibited no effects of soybean oil (Fig. 6D). The epicuticular wax on apple stem surfaces occurred as platelets (Fig. 6E). Similar to peach stems, the wax morphology of apple stems was not influenced by either soybean emulsion and/ or rain (Fig. 6F). Stomates were not observed on apple stems.

Epicuticular wax morphology and stomatal apparatus were not altered by soybean oil emulsions or rain. However, soybean oil emulsion induced stomatal closure in leaf as well as stem stomates of peach. Results herein clearly illustrated that rainfall of $2.54 \mathrm{~cm}$ was capable of washing off a major portion of the applied oil and thus, respraying may be required to improve the efficacy of applied soybean oil.

\section{Literature Cited}

Baker, E.A. 1974. The influence of environment on leaf wax development in Brassica oleraceae. New Phytol. 73:955-966.

Bondada, B.R., D.M. Oosterhuis, J.B. Murphy, and K.S. Kim. 1996. Effect of water stress on the epicuticular wax composition and ultrastructure of cotton leaf, bract, and boll. Environ. Expt. Bot. 36:61-69.

Bondada, B.R., D.M. Oosterhuis, S.D. Wullschleger, K.S. Kim, and W.H. Harris. 1994. Anatomical consideration related to photosynthesis in cotton leaves, bracts, and the capsule wall. J. Expt. Bot. 45:111-118.

Bondada, B.R, C.E. Sams, and D.E. Deyton. 1998. Gas exchange and wax morphology as influenced by soybean emulsions and rain. HortScience 33:115 (abstr.).

Davidson, N.A., J.E. Dibble, M.L. Flint, P.J. Marer, and A. Guye. 1991. Managing insects and mites with spray oils. Univ. of California, Oakland, Div. of Agr. and Natural Resources Publ. 3347.

Dybing, C.D. and H.B. Currier. 1961. Foliar penetration by chemicals. Plant Physiol. 36:169-174.

Fahn, A. 1990. Plant anatomy. Pergamon Press, Oxford, New York.

Ferree, D.C., F.R. Hall, and R.A. Spotts. 1976. Influence of spray adjuvants on multiple applications of benomyl and oil on photosynthesis of apples. HortScience 11:391-392.

Gudin, C., W.J. Syratt, and L. Boize. 1976. The mechanism of photosynthetic inhibition and the development of scorch in tomato plants treated with spray oils. Ann. Appl. Biol. 84:213-219.

Leece, D.R. 1976. Composition and ultrastructure of leaf cuticles from fruit trees, relative to differential foliar absorption. Austral. J. Plant Physiol. 3:833-847.

Mashaya, N. 1993. Effect of simulated rain on efficacy of insecticide deposits on tobacco. Crop Protection 12:55-58.

McDowell, L.L., G.H. Willis, L.M. Southwick, and S. Smith. 1984. Methyl parathion and EPN wash off from cotton plants by simulated rain. Environ. Sci. Technol. 18:423-427.

McWhorter, C.G. and W.L. Barrentine. 1988. Spread of paraffinic oil on leaf surfaces of Johnsongrass (Sorghum halepense). Weed Sci. 36:111117.

Meyer, H. and D.B. Anderson. 1968. Plant physiology. D. Van Nostrand Co., Inc., New York.

Myers, R.E., D.E. Deyton, and C.E. Sams. 1996. Applying soybean oil to dormant peach trees alters internal atmosphere, reduces respiration, delays bloom, and thins flower buds. J. Amer. Soc. Hort. Sci. 121:96-100.

Pick, F.E,L.P. van Dyk, and P.R. de Beer. 1984. The effect of simulated rain on deposits of some cotton pesticides. Pest. Sci. 15:616-623.

Pless, C.D, D.E. Deyton, and C.E. Sams. 1995. Control of San Jose scale, terrapin scale, and European red mite on dormant fruit trees with soybean oil. HortScience 30:94-97.

Reichard, D.L. and H. Zhu. 1996. A system to measure viscosities of spray mixtures at high shear rates. Pest. Sci. 47:137-143.

Schonherr, J. and M.J. Bukovac. 1972. Penetration of stomata by liquids: Dependence on surface tension, wettability, and stomatal morphology. Plant Physiol. 49:813-819.

Syvertsen, J.P. and M. Salyani. 1991. Petroleum spray oil effects on net gas exchange of grapefruit leaves at various vapor pressures. HortScience 26:168-170.

Turrell, F.M. 1947. Citrus leaf stomata: Structure, composition, and pore size in relation to penetration by liquids. Bot. Gaz. 108:476-483.

Van Overbeek, J. and R. Blondeau. 1954. Mode of action of phytotoxic oils. Weeds 3:55-65.

Wirth, W., S. Storp, and W. Jacobsen. 1991. Mechanisms controlling leaf retention of agricultural spray solutions. Pest. Sci. 33:411-420.

Wood, B.W. and J.A. Payne. 1986. Suppression of pecan net photosynthesis by crop oils. J. Entomol. Sci. 21:201-205. 